\title{
Silent RSV in infants with SARS-CoV-2 infection: a case series
}

\author{
Antonietta Giannattasio ${ }^{1}$, Marco Maglione ${ }^{1}$, Carolina D'Anna ${ }^{1}$, Stefania Muzzica ${ }^{1}$, \\ Francesca Angrisani ${ }^{1}$, Sabrina Acierno ${ }^{1}$, Alessandro Perrella ${ }^{2}$, and Vincenzo Tipo ${ }^{1}$ \\ ${ }^{1}$ AORN Santobono Pausilipon \\ ${ }^{2}$ AORN Cardarelli
}

April 8, 2021

\section{Silent RSV in infants with SARS-CoV-2 infection: a case series}

Antonietta Giannattasio, $\mathrm{MD}, \mathrm{PhD}^{1}$, Marco Maglione, $\mathrm{MD}, \mathrm{PhD}^{1}$, Carolina D'Anna, $\mathrm{MD}^{1}$, Stefania Muzzica, MD ${ }^{1}$,Francesca Angrisani, $\mathrm{MD}^{1}$, Sabrina Acierno, $\mathrm{MD}^{1}$, Alessandro Perrella ${ }^{2}, \mathrm{MD}, \mathrm{PhD}^{2}$, Vincenzo Tipo, $\mathrm{MD}^{1}$

${ }^{1}$ Santobono-Pausilipon Children's Hospital, Pediatric Emergency and Short Stay Unit, Naples, Italy

${ }^{2}$ Cardarelli Hospital, Infectious Disease-Health Policy Direction, Naples, Italy

Correspondingauthor:

Antonietta Giannattasio, MD, PhD

Pediatric Emergency and Short Stay Unit,

Santobono-Pausilipon Children's Hospital, Naples, Italy

+39 3392695959

antonella.giannattasio@virgilio.it

Keywords: SARS-CoV-2; respiratory syncytial virus; infants; outcome.

Abbreviated title: SARS-CoV-2 and VRS co-infection in infants

To the Editor,

We deeply commend Rotulo et al. in a recent issue of Pediatric Pulmonology on their hypothesis regarding the possible role of an undiagnosed severe acute respiratory syndrome coronavirus 2 (SARS-CoV-2)infection in determining a peak of severe cases of bronchiolitis during early 2020, just before the pandemic outbreak in Italy. ${ }^{1}$

Given the limited prevalence of severe SARS-CoV-2 infection in children compared to adults, the role of coexistent infection by other pathogens is of particular interest, as its potential to worsen the clinical expression of the disease is yet to be determined. During the SARS-CoV-2 pandemic, the number of accesses to emergency departments because of viral infections other than SARS-CoV-2 has been significantly lower in comparison to non-pandemic years. ${ }^{2}$ On the other hand, respiratory syncytial virus(RSV), the main responsible of bronchiolitis, representsa traditionally important cause of hospitalization in children under 12 months of age. ${ }^{1}$ To date, clinical course of SARS-CoV-2 and RSV co-infection has been poorly described and its impact on patients' outcomes has not been clarified.We described clinical features and outcome of 6 infants from the Coronavirus disease 2019 (COVID-19) Unit of a tertiary care pediatrichospital who were co-infected with both SARS-CoV-2 and RSV. 
A total of 97infants under 1 year of age with SARS-CoV-2 infection were hospitalized at our Pediatric COVID Unit between December $1^{\text {st }}, 2020$ and March $30^{\text {th }}, 2021$. Among them, 6 had SARS-CoV-2 and RSV coinfection at admission. SARS-CoV-2 was searched by real-time PCR (RT-PCR) on nasopharyngeal swab. RSV was searched by direct detection of viral antigens on nasopharyngeal swab. Patients' characteristics are reported inTable .

Patient 1 was admitted because of a 2-day-history of cough. Physical examination was unremarkable, with no respiratory distress or gastrointestinal symptoms and good oxygen saturation. Blood tests revealed a slight increase of C-reactive protein (CRP) levels, normal procalcitonin (PCT) and lymphomonocitosys. Chest $\mathrm{X}$-ray upon admission was normal.

Patient 2 was admitted for fever and cough occurred in the previous 24 hours. She had a previously diagnosed compensated interatrial defect. Parents were already positive to SARS-CoV-2 before hospital admission. At examination the infant had mild pharyngitis, coarse pulmonary cracklesand mild subcostal retractions. Blood laboratory investigations only showed lymphomonocytosis. During the hospital stay she presented no significant dyspnea or other symptoms.

Patient 3 was admitted fordyspneathat occurred a fewhours ago. Mother was positive for SARS-CoV-2. At admission the infant was alert with mild subcostal retractions and good oxygen saturation. Blood tests revealed elevated ferritin $(1054 \mathrm{ng} / \mathrm{ml}$, n.r. $<320)$ and monocytosis. Chest X-ray was unremarkable. During hospital stay she presented mild diarrhea with no dehydration.

Patient 4 was admitted for fever, whooping cough and vomiting occurred in the previous few hours. Both parents were already positive for SARS-CoV-2. At examination the infant had pharyngitis and a mild respiratory distress with an oxygen saturation of $95 \%$. Blood tests revealed lymphocytosis. The clinical course was unremarkable and no dyspnea or other symptoms occurred.

Patient 5 was admitted for fever occurred one day before. Parents resulted positive for SARS-CoV-2 infection. Blood tests showed high ferritin and lymphomonocytosis. Clinical course was unremarkable.

Patient 6 was admitted forrespiratory distress since the day before. She had a history a perinatal pneumothorax and a neonatal sepsis. Physical examination revealed sporadic rales. Chest X-ray showed small areas of linear consolidation in the left lower lobe. She had an unremarkable hospital stay.

No patient required oxygen supplementation or other treatments during the hospital stay.

Patients with SARS-CoV-2 infection can be co-infected with other respiratory viruses or bacterial pathogens. ${ }^{3}$ In adults, no significant difference in patient outcomes was observed between the simple SARSCoV-2 and co-infected groups. ${ }^{3}$ However, data on RSV-SARS-CoV-2 co-infected patients were not described separately. ${ }^{3}$ Whether the combined RSV-SARS-CoV-2 infection in infants results in worse clinical expression compared to the infection by the single viruses is still unclear. Jiang et al reported a child infected with SARS-COV-2, RSV and human metapneumovirus who developed severe respiratory symptoms requiring intensive care, with ground glass opacities at chest computed tomography. ${ }^{4}$ This finding, typical of COVID-19, suggested that the main responsible of the severe clinical course in this patient was SARS-CoV-2 rather than the other 2 viruses detected.Similarly, Rotulo and coworkers hypothesized a role of SARS-CoV2 in the more severe course of cases of bronchiolitis occurred during the first 3 months of $2020 .{ }^{1}$ They reported that, in comparison to previous years, during early 2020 a higher proportion of infants with bronchiolitis required oxygen supplementation. ${ }^{1}$ Nevertheless, their reasonable speculations mostly rely on the assumption that SARS-CoV-2was likely to circulate in Italy already since the end of 2019, but are not supported by viral detection, as at the time RT-PCR for this pathogen was not available yet.Our data do not support the hypothesis that the combined RSV-SARS-CoV-2 infection leads to a more severe clinical picture, as our patients only presented mild fever and respiratory symptoms with an uncomplicated evolution.

These apparently conflicting data likely derive from the patients included in the available studies. Indeed, RSV is known to be of scarce clinical relevance in adults, but it may cause severe respiratory disease in infants. Therefore, one could speculate that no worse clinical expression was found in patients with combined RSV 
and SARS-CoV-2 infection due to the fact that in adults RSV is generally not responsible for significant symptoms. However, unexpectedly, our results confirm that, also in infants, RSV coexistence does not worsen COVID-19 symptoms. A very recent study showed that pathways for over-expressed genes are highly concordant between patients with SARS-CoV-2 and non-SARS-CoV-2 viral infections. ${ }^{5}$ We can speculate that, in co-infected patients, increased SARS-CoV-2 viral replication may occur compared to concomitant other viruses, due to the characteristics of infectivity and replication of SARS-CoV-2. As COVID-19 in children is a mild disease in the majority of cases ${ }^{6}$ it is possible to hypothesize that, in co-infected children, SARS-CoV-2 overbears RSV, inhibiting its replication and thus its clinical expression. Further studies are mandatory in order to investigate the clinical course of RSV in infants with a concomitant SARS-CoV-2 infection.

Competing interests: Authors state no conflict of interest.

\section{References:}

1. Rotulo GA, Casalini E, Brisca G, Piccotti E, Castagnola E. Unexpected peak of bronchiolitis requiring oxygen therapy in February 2020: Could an undetected SARS-CoV2-RSV co-infection be the cause? PediatrPulmonol . 2021 Mar 3. (Online ahead of print).

2. Dopfer C, Wetzke M, ZychlinskyScharff A,Mueller F,Dressler F, Baumann U, Sasse M, Hansen G, Jablonka A, Happle C. COVID-19 related reduction in pediatric emergency healthcare utilization-a concerning trend.BMC Pediatr. 20, 427 (2020).

3. Ma L, Wang W, Le Grange JM, Wang X, Du S, Li C, Wei J, Zhang JN. Coinfection of SARS-CoV-2 and Other Respiratory Pathogens.Infect Drug Resist . 2020;13:3045-3053.

4. Jiang S, Liu P, Xiong G, Yang Z, Wang M, Li Y, Yu X. Coinfection of SARS-CoV-2 and multiple respiratory pathogens in children. ClinChem Lab Med.2020;58:1160-1161.

5. Thair SA, He YD, Hasin-Brumshtein Y, Sakaram S, Pandya R, Toh J, Rawling D, Remmel M, Coyle S, Dalekos GN, et al. Transcriptomic similarities and differences in host response between SARS-CoV-2 and other viral infections. iScience. 2021;24:101947.

6. Garazzino S, Montagnani C, Donà D, Meini A, Felici E, Vergine G, Bernardi S, Giacchero R, Lo Vecchio A, Marchisio P, et al.; Italian SITIP-SIP Pediatric Infection Study Group; et al. Italian SITIPSIP SARS-CoV-2 paediatric infection study group. Multicentre Italian study of SARS-CoV-2 infection in children and adolescents, preliminary data as at 10 April 2020. Euro Surveill. 2020;25:2000600.

Table. Characteristics of 6 infants with SARS-CoV-2 and RSV co-infection

\begin{tabular}{|c|c|c|c|c|c|c|}
\hline & Patient 1 & Patient 2 & Patient 3 & Patient 4 & Patient 5 & Patient 6 \\
\hline$\overline{\text { Age }}$ & 19 days & 9 months & 18 days & 7 months & 24 days & 2 month \\
\hline Gender & $\mathrm{F}$ & $\mathrm{F}$ & $\mathrm{F}$ & M & M & $\mathrm{F}$ \\
\hline $\begin{array}{l}\text { Gestational } \\
\text { age } \\
\text { (weeks) }\end{array}$ & 38 & 39 & 37 & 40 & 39 & 37 \\
\hline $\begin{array}{l}\text { Duration } \\
\text { of hospital } \\
\text { stay (days) }\end{array}$ & 4 & 2 & 7 & 1 & 3 & 3 \\
\hline $\begin{array}{l}\text { Peak tem- } \\
\text { perature } \\
\left({ }^{\circ} \mathrm{C}\right)\end{array}$ & 37.1 & 36.5 & 37.8 & 38 & 39 & 36.8 \\
\hline $\begin{array}{l}\text { Lowest } \\
\text { oxygen } \\
\text { saturation } \\
\text { (\%) } \\
\text { Clinical } \\
\text { findings: }\end{array}$ & 99 & 95 & 98 & 95 & 99 & 100 \\
\hline
\end{tabular}




\begin{tabular}{|c|c|c|c|c|c|c|}
\hline & Patient 1 & Patient 2 & Patient 3 & Patient 4 & Patient 5 & Patient 6 \\
\hline Systemic & - & - & Fever & - & Fever & - \\
\hline Respiratory & Cough & $\begin{array}{l}\text { Cough, big } \\
\text { bubble rales, } \\
\text { slight } \\
\text { subcostal } \\
\text { retraction }\end{array}$ & $\begin{array}{l}\text { Dyspnea, } \\
\text { slight } \\
\text { subcostal } \\
\text { retraction }\end{array}$ & $\begin{array}{l}\text { Mild } \\
\text { respiratory } \\
\text { distress }\end{array}$ & Unremarkable & Sporadic rales \\
\hline $\begin{array}{l}\text { Gastrointestinal } \\
\text { Inflammatory } \\
\text { index: }\end{array}$ & - & - & Diarrhea & Vomit & - & - \\
\hline $\begin{array}{l}\text { CRP highest } \\
\text { value }\end{array}$ & 7.39 & 1.53 & 1.57 & 1.01 & 1.32 & 1.27 \\
\hline $\begin{array}{l}\text { PCT highest } \\
\text { value }\end{array}$ & 0.1 & 0.06 & 0.13 & 0.08 & 0.22 & 0.14 \\
\hline $\begin{array}{l}\text { Ferritin } \\
\text { highest value }\end{array}$ & 338 & 58.8 & 1054 & 39.4 & 671 & 36 \\
\hline Blood & 15.761 .88 & 13.503 .73 & 9.492 .39 & 23.197 .94 & 11.303 .16 & 9.582 .18 \\
\hline $\begin{array}{l}\text { count } \\
\left(\mathbf{x} 10^{9}\right. \\
\text { cells/L): } \\
\text { Leukocytes } \\
\text { Neutrophils } \\
\text { Lympho- } \\
\text { cytes } \\
\text { Monocytes }\end{array}$ & 11.382 .33 & 7.152 .52 & 4.202 .54 & 12.242 .85 & 5.992 .11 & 6.061 .23 \\
\hline
\end{tabular}

CRP: C-reativeprotein (n.v. $<5 \mathrm{mg} / \mathrm{L}$ ); PCT: procalcitonin (n.v. $<0.5 \mathrm{ng} / \mathrm{ml}$ ); ferritin: n.v. $<320 \mathrm{ng} / \mathrm{ml}$ 